re-intubation was not needed for at least 48h. Brain sonography was done befor extubation and after $48^{\mathrm{h}}$.sample size was determined with $95 \%$ confidence and $90 \%$ power. Data was analyzed with spss 11.5 and Chi-square test.

Results There were no significant differences in clinical characteristics between the two groups at randomization.

Fifty-four percent (14/25) infants were successfully extubated to NSIMV compared with $52 \%(13 / 25)$ to NCPAP $(p=0.78)$. Infants assigned to NCPAP had higher arterial $\mathrm{CO}_{2}$ pressure level than those assigned to NSIMV ( $\mathrm{p}=0.002$ ).

Neither procedure induced major adverse effects despite more elevation in IVH grade during SIMV.

Conclusions NSIMV in the post-extubation period is safe, however it's not more effective than NCPAP in preventing re-ventilation.

\section{THE PREDICTIVE FACTORS IN THE PROGRESS OF TRANSIENT TACHYPNEA OF THE NEWBORN}

doi:10.1136/archdischild-2012-302724.1781

E Okulu, D Kahvecioğlu, A Kılıç, S Alan, IM Akin, B Atasay, S Arsan. Department of Pediatrics, Division of Neonatology, Ankara University, Ankara, Turkey

Aim To determine the clinical risk factors to predict the progress of TTN in late-preterm and term infants.

Methods The infants with the diagnosis of TTN were evaluated retrospectively. Patients were divided into two groups according to the intensity of respiratory support. Group-1 received any ventilatory support, where group-2 only oxygen. Clinical findings, Richardson and Silverman scores were compared.

Results One-hundred-six (19.1\%) infants were evaluated (68 in group-1, 38 in group-2). Mean gestational age and birth weight were lower in group-2. The $\mathrm{C} / \mathrm{S}$ and male gender rates were similar. Richardson scores, Silverman scores, peak-respiratory rates ( $p R R$ ) and oxygen need $\left(\mathrm{FiO}_{2}\right)$ in the first 24-hours were higher, duration of respiratory support and hospitalization were longer in group-1. The cut-off for Richardson score was 3 , and patients whose score higher than 3 had a 6.98-fold-risk, the cut-off for Silverman score was 5 and whose score higher than 5 had a 7.46-fold risk, and the cut-off for $\mathrm{pRR}$ in first 24-hours was $75 / \mathrm{min}$ and whose $\mathrm{pRR}$ was higher than $75 / \mathrm{min}$ in first 24 -hours had a 1.10-fold risk of receiving ventilatory support (95\%CI: 2.30-21.18, 2.54-21.89, and 1.035-1.17, $\mathrm{p}<0.01$, respectively).

Conclusions TTN, is usually a benign and self-limited disease and the prognosis is generally excellent. Assessment of Richardson score, Silverman score, and $\mathrm{pRR}$ in first 24-hours of patients may be useful in predicting clinical course of TTN. So by predicting of the intensity for ventilatory support in the patients, it is important to plan and provide the appropriate level of care for these infants.

\section{ENDOTRACHEAL TUBE POSITION IN VENTILATED NEONATES - DOES EVIDENCE INFLUENCE PRACTICE?}

doi:10.1136/archdischild-2012-302724.1782

'G Peh, 'R Ebel, 1,2A Sinha, ${ }^{1,2}$ S Kempley, 'S Mohinuddin. 'Neonatal Transfer Service, Barts Health NHS Trust; ${ }^{2}$ Barts and The London School of Medicine and Dentistry, London, UK

Background Malpositioned endotracheal tubes (ETT) in ventilated neonates are associated with adverse pulmonary outcomes including unequal surfactant delivery, asymmetric lung expansion and air-leaks. ${ }^{1}$ Use of gestation age (GA) based guideline to determine the ETT length at lips resulted in reduction of the need for ETT repositioning from $53 \%$ to $8 \% .{ }^{2}$ This guideline is recommended by ILCOR. ${ }^{3}$

Aim To assess adherence to guidelines and need for ETT repositioning.
Methods Ventilated neonates $<24$ hours of age, transferred by a regional transfer service during study periods of January to March (3-months) in the years 2008 (pre-publication ${ }^{2}$ ) and 2011 (postpublication ${ }^{2}$ ) were included. Demographic data, ETT size, length at upper-lip, position on chest X-ray and need for repositioning were collected.

Results Similar proportion of ETT's were repositioned during 2008 and 2011 (30\% vs 37\%, p=0.59). During both periods the proportion of ETT's repositioned were significantly higher $(p<0.05)$ with greater deviation of ET length insertion from the guideline:

\begin{tabular}{lcc}
\hline Inserted ETT length & $\begin{array}{c}\text { Need for repositioning } \\
(\mathbf{2 0 0 8 )}\end{array}$ & $\begin{array}{c}\text { Need for repositioning } \\
(\mathbf{2 0 1 1 )}\end{array}$ \\
\hline ETT at recommended length & $3 / 15(20 \%)$ & $3 / 20(15 \%)$ \\
$E \Pi T+-0.5 \mathrm{~cm}$ deviation from guideline & $9 / 36(25 \%)$ & $7 / 21(33 \%)$ \\
ETT $>0.5 \mathrm{~cm}$ deviation from guideline & $9 / 15(60 \%)$ & $16 / 29(55 \%)$ \\
\hline
\end{tabular}

Conclusion Adherence to guideline is associated with significant reduction in need for ETT repositioning. Publication of guideline has had limited effect. There is need for improving dissemination of evidence based guidelines to improve outcomes.

1. Thayyil et al. Am J Perinatol 2008.

2. Kempley et al. Resuscitation 2008.

3. Richmond et al. Resuscitation 2010.

\section{HOW SAFE ARE DELIVERY ROOM MANEGEMENTS TO PREVENT EARLY HYPOCARBIA?}

doi:10.1136/archdischild-2012-302724.1783

E Okulu, IM Akin, S Alan, A Kilıc, B Atasay, S Arsan. Department of Pediatrics, Division of Neonatology, Ankara University, Ankara, Turkey

Background and Aim Clinically determining appropriate respiratory support from the point of delivery to the NICU is difficult and inadvertent overventilation may be common. The aim of the study was to determine whether delivery room managements done by skilled team will produce 'normocarbic' blood gas values in $<29$ weeks' preterm infants.

Method A prospective cohort study was designed and infants born before 29 weeks' from January 2009 to December 2011 were enrolled. All infants received $100 \mathrm{mg} / \mathrm{kg}$ prophylactic surfactant in delivery room. During resuscitation, stabilization, surfactant administration and transport infants were ventilated with a T-piece resuscitator. If respiratory drive was present, infants were extubated to nasal CPAP through short binasal prong. $\mathrm{FiO}_{2}$ was adjusted to achive $\mathrm{SaO}_{2}$ of $88-92 \%$ which was monitored by pulse oxymeter. Carbon dioxide $\left(\mathrm{CO}_{2}\right)$ levels on admission and early NICU hours (0-6 hours) were evaluated.

Results Fifty nine infants were included with a mean gestation age of 26.2 \pm 1.7 (23-28.6) weeks and a birth weight of $857 \pm 237$ (4001470). The mean $\mathrm{pCO}_{2}$ levels of the first blood gas analysis was $45.3 \pm 9.8$ (range 30.4-71.2). Four (6.8\%) infants had hypocarbia $\left(\mathrm{pCO}_{2}<35 \mathrm{mmHg}\right)$.

Conclusion To prevent both hyperoxia and hypocarbia from the point of delivery to the NICU is a challenge. More caution is required to prevent hypocarbia and hyperoxia.

\section{RESPIRATORY MORBIDITY IN TERM INFANTS DELIVERED BY ELECTIVE CAESAREAN SECTION: COHORT STUDY}

doi:10.1136/archdischild-2012-302724.1784

${ }^{1} \mathrm{~A}$ Troshani, ${ }^{2} \mathrm{E}$ Tushe, ${ }^{2} \mathrm{G}$ Gora, ${ }^{3} \mathrm{E}$ Vevecka. ${ }^{1}$ Obstetric-Gynecologic University Hospital Nr 1; ${ }^{2}$ Pediatric Department, Obstetric-Gynecologic University Hospital Nr 1, Tirana; ${ }^{3}$ Pediatric Department, University Hospital 'Mother Thereza, Tirane, Albania 